\title{
max \\ Impact of Iterative Deuterium Annealing in Long-Channel MOSFET Performance
}

\author{
Dong-Hyun Wang ${ }^{1,+}$, Ja-Yun Ku ${ }^{1,+}{ }^{+}$, Dae-Han Jung ${ }^{1}$, Khwang-Sun Lee ${ }^{1}$, Woo Cheol Shin ${ }^{2}$, Byung-Do Yang ${ }^{1}$ \\ and Jun-Young Park $1, *$ (i)
}

1 School of Electronics Engineering, Chungbuk National University, Cheongju 28644, Korea; dh.wang@chungbuk.ac.kr (D.-H.W.); kujayun0@chungbuk.ac.kr (J.-Y.K.); jungdh@chungbuk.ac.kr (D.-H.J.); ksunlee@chungbuk.ac.kr (K.-S.L.); bdyang@cbnu.ac.kr (B.-D.Y.)

2 School of Electrical Engineering, Korea Advanced Institute of Science and Technology (KAIST), Daejeon 34141, Korea; 8wave8@kakao.com

* Correspondence: junyoung@cbnu.ac.kr

+ These authors contributed equally to this work.

Citation: Wang, D.-H.; Ku, J.-Y.; Jung,

D.-H.; Lee, K.-S.; Shin, W.C.; Yang,

B.-D.; Park, J.-Y. Impact of Iterative Deuterium Annealing in LongChannel MOSFET Performance. Materials 2022, 15, 1960. https:// doi.org/10.3390/ma15051960

Academic Editors: Cecilia Mortalò, Silvia Maria Deambrosis and Valentina Zin

Received: 18 January 2022

Accepted: 4 March 2022

Published: 7 March 2022

Publisher's Note: MDPI stays neutral with regard to jurisdictional claims in published maps and institutional affiliations.

Copyright: (c) 2022 by the authors. Licensee MDPI, Basel, Switzerland. This article is an open access article distributed under the terms and conditions of the Creative Commons Attribution (CC BY) license (https:// creativecommons.org/licenses/by/ $4.0 /)$.

\begin{abstract}
In contrast to conventional forming gas annealing (FGA), high-pressure deuterium annealing (HPD) shows a superior passivation of dangling bonds on the $\mathrm{Si} / \mathrm{SiO}_{2}$ interface. However, research detailing the process optimization for HPD has been modest. In this context, this paper demonstrates the iterative impact of HPD for the better fabrication of semiconductor devices. Longchannel gate-enclosed FETs are fabricated as a test vehicle. After each cycle of the annealing, device parameters are extracted and compared depending on the number of the HPD. Based on the results, an HPD condition that maximizes on-state current $\left(\mathrm{I}_{\mathrm{ON}}\right)$ but minimizes off-state current $\left(\mathrm{I}_{\mathrm{OFF}}\right)$ can be provided.
\end{abstract}

Keywords: annealing; forming gas annealing; gate-enclosed MOSFET; high pressure deuterium annealing; post metal annealing

\section{Introduction}

As semiconductor devices are scaled down to improve the packing density and device performance, device reliability, associated with the gate dielectric, has been degraded. Since the equivalent oxide thickness (EOT) is extremely scaled for a better gate controllability, devices are more vulnerable to damage stemming from hot-carrier injection (HCI), biastemperature instability (BTI), Fowler-Nordheim Tunneling (F-N) tunneling, and even total ionizing dose (TID) [1]. As a consequence, increased gate leakage $\left(\mathrm{I}_{\mathrm{G}}\right)$ as well as threshold voltage $\left(\mathrm{V}_{\mathrm{TH}}\right)$ mismatching are inevitable.

Various fabrication processes to improve the gate dielectric reliability such as lightly doped draining [2], fluorine ion implantation [3], forming gas annealing [4], and electrothermal annealing [5] have been proposed. In particular, high pressure deuterium annealing (HPD), which is performed under deuterium ambient diluted by nitrogen, is promising for modern device fabrication. HPD enables dangling bond passivation at the $\mathrm{Si} / \mathrm{SiO}_{2}$ interface [6-8]. The passivated Si-D bonding is difficult to break compared to $\mathrm{Si}-\mathrm{H}$, and hence the device lifetime can be further improved.

In the past, the HPD process has been preferred to improve the reliability of the NAND flash memory [9]. However, nowadays, HPD has been applied to the mass production of state-of-the-art logic transistors [10] as well as cell DRAM [11].

In contrast to conventional forming gas annealing (FGA), which is performed under atmospheric pressure, HPD requires a higher pressure. Hence, additional processing equipment such as a reaction chamber is required to perform HPD. Moreover, the deuterium gas mixture is difficult to supply compared to diluted hydrogen. In this context, even though the impacts of HPD on the reliability of semiconductor devices are noticeable, 
research on the process optimization for HPD, e.g., considering the annealing time, number of annealing cycles, annealing temperature, diluted deuterium concentration, etc., has been very modest. For example, the annealing time and temperature for HPD were fixed at $60 \mathrm{~min}$ and $400{ }^{\circ} \mathrm{C}$, respectively [6-8]. In other words, it is difficult to figure out how long and at what temperature HPD should be applied to maximize the device reliability.

In this article, the impact of iterative HPD is demonstrated for the first time. After the MOSFET fabrication on a silicon wafer, HPD is performed for several cycles. Then, based on the measured DC characteristics, the extracted device parameters are compared according to the number of HPD cycles. Based on the results, an optimized HPD cycle is proposed to maximize device reliability.

\section{Experimental Details}

In order to solely investigate the impact of deuterium annealing, the materials as well as device structure and fabrication processing for a test vehicle (TV) were extremely minimized. Gate-enclosed n-MOSFETs were fabricated on a p-type (100) bulk-Si wafer, as shown in Figure 1. The gate dielectric was thermally oxidized with a $30 \mathrm{~nm}$ thickness, and a $170 \mathrm{~nm}$ thickness of $\mathrm{n}^{+}$poly-Si for the gate electrode was deposited by low-pressure chemical vapor deposition (LPCVD). After the gate patterning, arsenic was implanted by a self-aligned process, and rapid thermal annealing (RTA) was performed at $1000{ }^{\circ} \mathrm{C}$ for $10 \mathrm{~s}$. Finally, the wafer was fab-out without metallization and post metal annealing such as FGA. The gate length (L) was varied from $5 \mu \mathrm{m}$ to $50 \mu \mathrm{m}$, and the channel width (W) was fixed at $280 \mu \mathrm{m}$. Then, 79 gate-enclosed n-MOSFETs were annealed several times under diluted deuterium at $450{ }^{\circ} \mathrm{C}$ for $60 \mathrm{~min}$. The annealing-to-annealing time difference for each cycle was less than $12 \mathrm{~h}$.
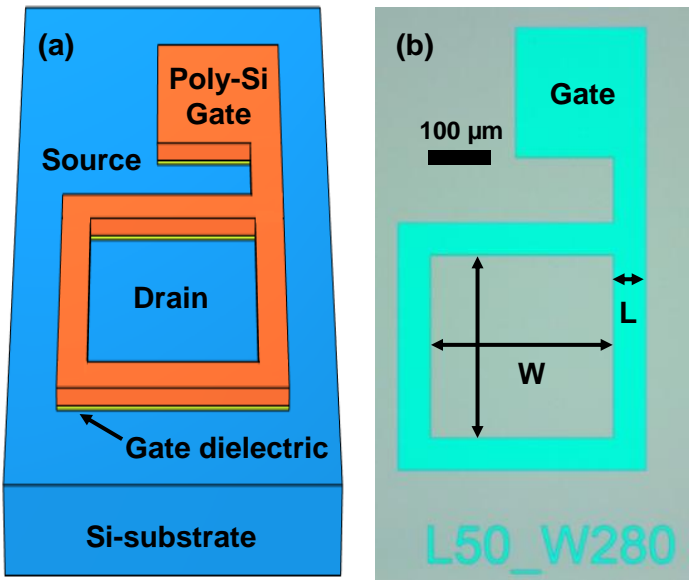

Figure 1. (a) Schematic and (b) optical microscope image of test vehicle on which silicon substrate is fabricated.

After the end of each annealing cycle, the 79 samples were measured using a parameter analyzer (B1500A) under ambient air at room temperature. The $\mathrm{V}_{\mathrm{TH}}$ was extracted using a constant current method at $\mathrm{I}_{\mathrm{D}}$ of $\mathrm{W} / \mathrm{L} \times 10^{-7} \mathrm{~A}$ [12], and the subthreshold swing (SS) was extracted between the $\mathrm{I}_{\mathrm{D}}$ at $\mathrm{V}_{\mathrm{TH}}$ and at two orders below. The detailed annealing conditions for the overall experiments are summarized in Table 1. Figure 2 shows the measured $I_{D}-V_{G}$ and $I_{D}-V_{D}$ characteristics of a fabricated TV device before HPD. 
Table 1. Summary of device sizes and annealing conditions.

\begin{tabular}{cc}
\hline Parameters & Value \\
\hline Gate length $(\mu \mathrm{m})$ & 5 to 50 \\
\hline Channel width $(\mu \mathrm{m})$ & 280 \\
\hline Equivalent oxide thickness $(\mathrm{nm})$ & 30 \\
\hline Gas mixture for annealing $(\%)$ & $\mathrm{N}_{2}: \mathrm{D}_{2}=96: 4$ \\
\hline Annealing temperature and pressure & $450{ }^{\circ} \mathrm{C}, 5$ bar \\
\hline Annealing time for a cycle (min) & 60 \\
\hline Number of samples $(\#)$ & 79 \\
\hline
\end{tabular}

(a)

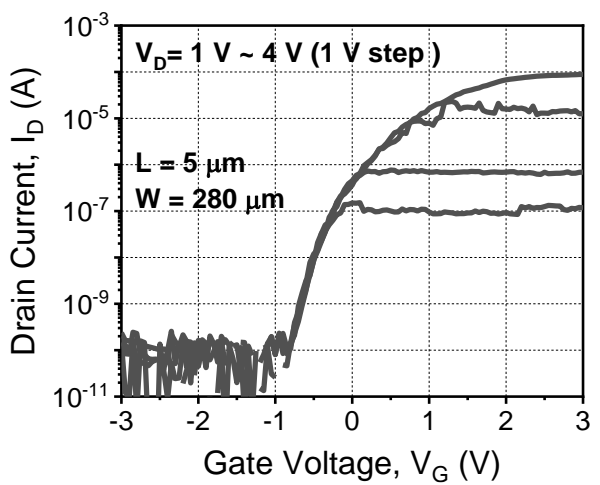

(b)

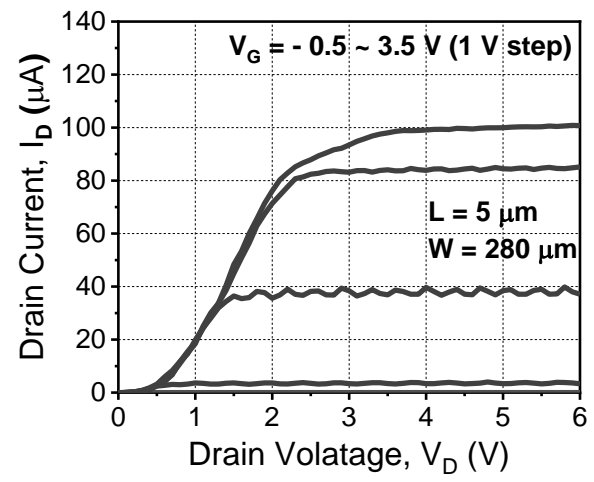

Figure 2. Measured (a) $\mathrm{I}_{\mathrm{D}}-\mathrm{V}_{\mathrm{G}}$ and (b) $\mathrm{I}_{\mathrm{D}}-\mathrm{V}_{\mathrm{D}}$ characteristics of fabricated TV device before deuterium annealing.

\section{Results and Discussion}

Figure 3a shows the measured $\mathrm{I}_{\mathrm{D}}-\mathrm{V}_{\mathrm{G}}$ characteristic of the fabricated device after iterative deuterium annealing. The SS improved as the number of deuterium annealing processes increased.

(a)

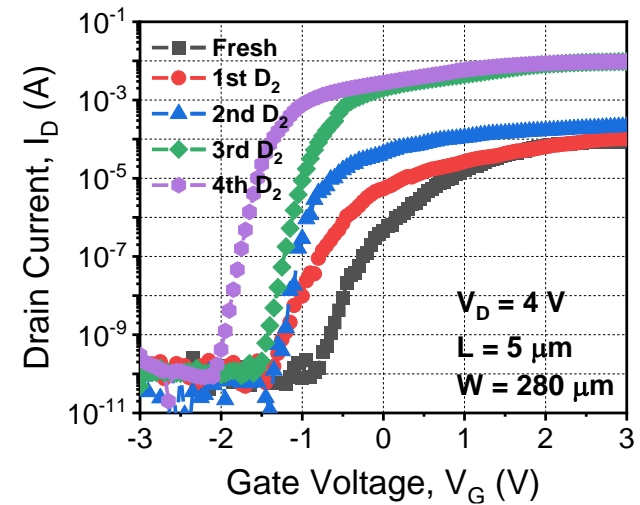

(b)

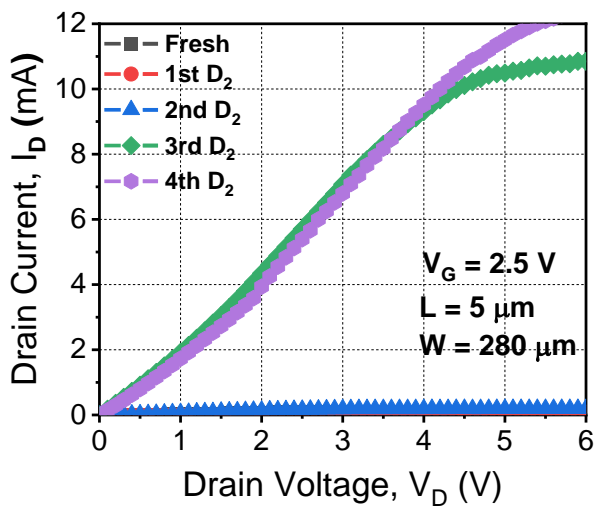

Figure 3. Measured (a) $I_{D}-V_{G}$ and (b) $I_{D}-V_{D}$ characteristics of the fabricated device after iterative deuterium annealing.

$\mathrm{V}_{\mathrm{TH}}$ shifted negatively because of the reduced SS as deuterium annealing was performed. Moreover, the drain output performance dramatically improved, as shown in Figure $3 b$. To elaborate, Figure 4 shows the extracted device parameters after deuterium annealing. 
(a)

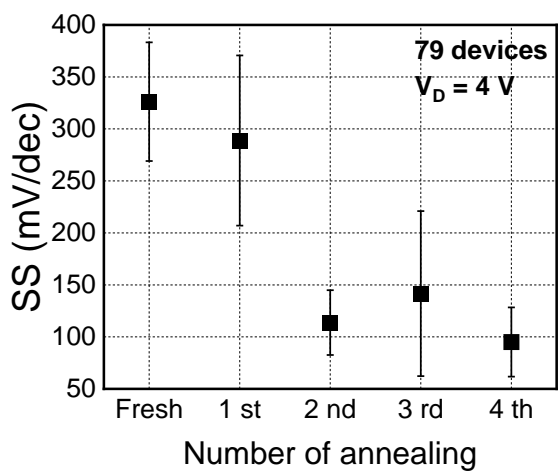

(c)

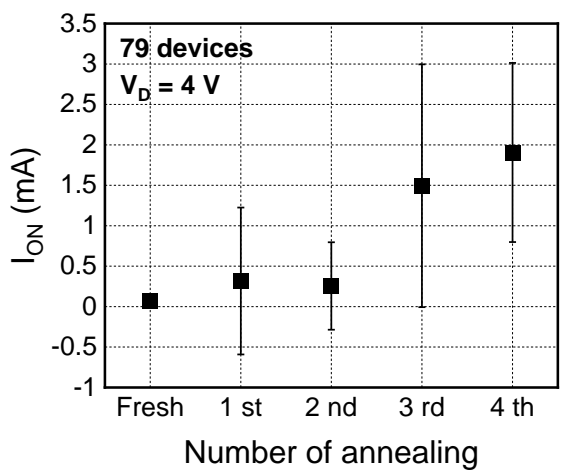

(b)

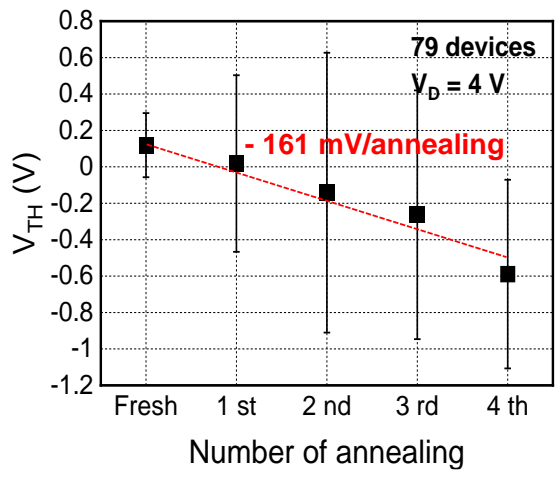

(d)

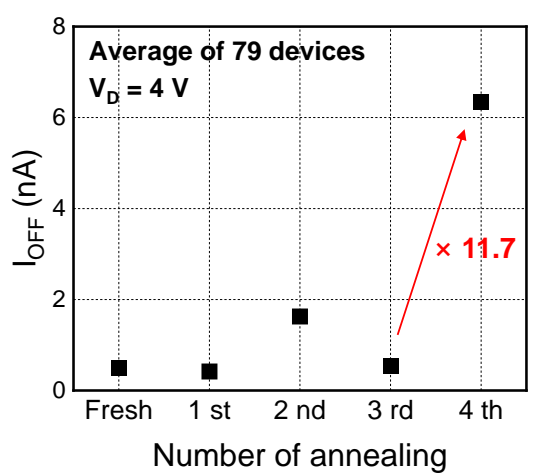

Figure 4. Extracted device parameters such as (a) $\mathrm{SS},(\mathbf{b}) \mathrm{V}_{\mathrm{TH}},(\mathbf{c}) \mathrm{I}_{\mathrm{ON}}$, and (d) $\mathrm{I}_{\mathrm{OFF}}$ after iterative HPD. The symbol and error bar indicate the average value and standard variation, respectively. ION and $\mathrm{I}_{\mathrm{OFF}}$ were extracted at $\mathrm{V}_{\mathrm{G}}=\mathrm{V}_{\mathrm{TH}}+2 \mathrm{~V}$ and $\mathrm{V}_{\mathrm{G}}=\mathrm{V}_{\mathrm{TH}}-2 \mathrm{~V}$, respectively.

The extracted average SS of the initial TV devices without HPD was $326 \mathrm{mV} / \mathrm{dec}$, but changed to $288,113,141$, and $95 \mathrm{mV} / \mathrm{dec}$ as the HPD cycle increased, as shown in Figure 4a. The reduced SS characteristic indicates that is possible to supply sufficient deuterium for the $\mathrm{Si}-\mathrm{D}$ passivation of the $\mathrm{Si} / \mathrm{SiO}_{2}$ interface, as the HPD cycle increases. In other words, the reduced interface trap density $\left(\mathrm{D}_{\mathrm{it}}\right)$ induced by the HPD leads to the reduction in SS. The $\mathrm{V}_{\mathrm{TH}}$ shifted linearly with the HPD cycles because of the reduced $\mathrm{SS}$, as shown in Figure $4 \mathrm{~b}$. The fitted $\mathrm{V}_{\mathrm{TH}}$ sensitivity was $-161 \mathrm{mV}$ per HPD cycle. In this context, excessive deuterium annealing should be considered in advance to avoid unwanted $\mathrm{V}_{\mathrm{TH}}$ mismatching. The on-state current $\left(\mathrm{I}_{\mathrm{ON}}\right)$ as well as the off-state current $\left(\mathrm{I}_{\mathrm{OFF}}\right)$ are the most representative parameters determining the device performance. $\mathrm{I}_{\mathrm{ON}}$ improved further as the number of annealing cycles increased. Iterative HPD annealing increases carrier mobility by eliminating traps at the $\mathrm{Si} / \mathrm{SiO}_{2}$ interface. Hence, by boosting mobility, $\mathrm{I}_{\mathrm{ON}}$ is improved. Considering that most research papers have focused only on 60 min of annealing time, the impact of iterative HPD in terms of $I_{\mathrm{ON}}$ improvement is noticeable [7-9]. However, applying excessive HPD for more than four cycles leads to an increasing $\mathrm{I}_{\mathrm{OFF}}$, as shown in Figure $4 \mathrm{~d}$. It can be inferred that the increment in $\mathrm{I}_{\mathrm{OFF}}$ after four cycles of HPD annealing is related to deuterium dissociation, etc., but this is difficult to conclude without analyzing the results of secondary ion mass spectrometry (SIMS). Based on the measured results, performing HPD is recommended for up to three cycles (180 min), allowing us to maximize $\mathrm{I}_{\mathrm{ON}}$ without increasing $\mathrm{I}_{\mathrm{OFF}}$.

Figure 5 shows the extracted $\mathrm{I}_{\mathrm{G}}$ of fabricated TV devices to investigate the device reliability. From the viewpoint of device reliability, HPD annealing prolongs the device lifespan and improves immunity against various electrical stresses during operation (e.g., hot-carrier injection, bias-temperature instability, and Fowler-Nordheim stress) [13-17]. In the same vein, the $\left|\mathrm{I}_{\mathrm{G}}\right|$ gradually decreased until three cycles of HPD. However, when HPD 
was performed for more than four cycles, the $\left|\mathrm{I}_{\mathrm{G}}\right|$ increased again. This result coincides with the results shown in Figure 4. Even though one cannot determine whether three cycles of annealing is universal for short-channel devices as well, one can at least conclude that there is an optimal number of HPD cycles for the fabrication of long-channel FETs.

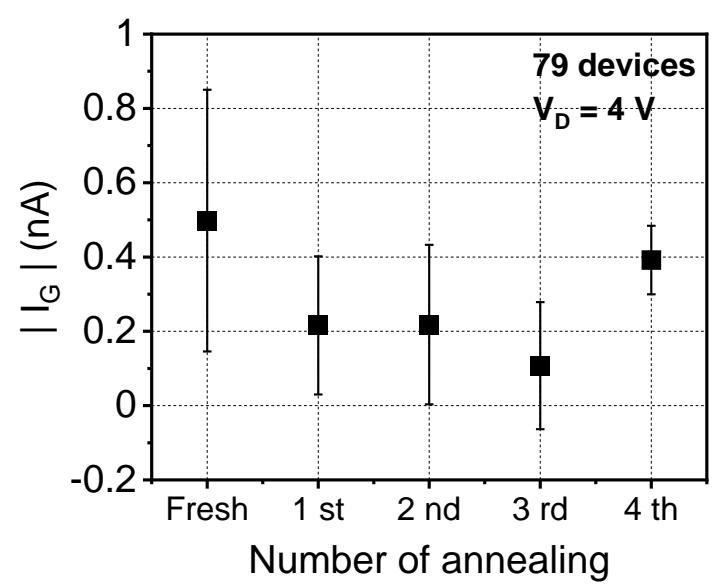

Figure 5. Extracted gate leakage $\left(I_{G}\right)$ after iterative $H P D$. The $I_{G}$ was extracted at $V_{G}=-3 V$.

\section{Conclusions}

High pressure deuterium annealing (HPD) has been favorably utilized for better device performance and reliability. The impact of iterative HPD was demonstrated in long-channel MOSFETs fabricated on silicon. The device output performance such as the on-state current $\left(\mathrm{I}_{\mathrm{ON}}\right)$ further improved as the number of HPD cycles increased. However, an excessive HPD of more than four cycles (longer than $180 \mathrm{~min}$ ) is expected to cause an unwanted threshold voltage $\left(\mathrm{V}_{\mathrm{TH}}\right)$ mismatch as well as an increased off-state current $\left(\mathrm{I}_{\mathrm{OFF}}\right)$. It was revealed that deuterium annealing, when unconditionally performed for a long time, is not effective; hence, this paper can provide a guideline for better device fabrication.

Author Contributions: J.-Y.P. conceived this project and designed all the experiments. D.-H.W. and J.-Y.K. conducted all the experiments and wrote this paper. D.-H.J. and K.-S.L. fabricated the devices. B.-D.Y. and W.C.S. designed the experiments and analyzed the measured data. All authors have read and agreed to the published version of the manuscript.

Funding: This work was supported by the National Research Foundation of Korea (NRF) grant funded by the Korea government (MIST) (No. 2020M3H2A1076786 and 2021R1F1A1049456). The EDA tool was supported by the IDEC.

Institutional Review Board Statement: Not applicable.

Informed Consent Statement: Not applicable.

Data Availability Statement: Not applicable.

Conflicts of Interest: The authors declare no conflict of interest.

\section{References}

1. Roy, K.; Mukhopadhyay, S.; Mahmoodi-Meimand, H. Leakage current mechanisms and leakage reduction techniques in deepsubmicrometer CMOS circuits. IEEE Electron Device Lett. 2003, 91, 305-327. [CrossRef]

2. Ogura, S.; Tsang, P.J.; Walker, W.W.; Critchlow, D.L.; Shepard, J.F. Design and Characteristics of the Lightly Doped Drain-Source (LDD) Insulated Gate Field-Effect Transistor. IEEE J. Solid-State Circuits 1980, 15, 424-432. [CrossRef]

3. Hook, T.B.; Adler, E.; Guarin, F.; Lukaitis, J.; Rovedo, N.; Schruefer, K. The effects of fluorine on parametrics and reliability in a 0.18- $\mu \mathrm{m} 3.5 / 6.8 \mathrm{~nm}$ dual gate oxide CMOS technology. IEEE Trans Electron Devices 2001, 48, 1346-1353. [CrossRef]

4. Razouk, R.R.; Deal, B.E. Dependence of interface state density on silicon thermal oxidation process variables. J. Electrochem. Soc. 1979, 126, 1573. [CrossRef]

5. Park, J.-Y.; Moon, D.-I.; Lee, G.-B.; Choi, Y.-K. Curing of Aged Gate Dielectric by the Self-Heating Effect in MOSFETs. IEEE Trans. Electron Devices 2020, 67, 777-788. [CrossRef] 
6. Kizilyalli, I.C.; Lyding, J.W.; Hess, K. Deuterium post-metal annealing of MOSFET's for improved hot carrier reliability. IEEE Electron Device Lett. 1997, 18, 81-83. [CrossRef]

7. Clark, W.F.; Ference, T.G.; Hook, T.B.; Watson, K.M.; Mittl, S.W.; Burnham, J.S. Process stability of deuterium-annealed MOSFET's IEEE Electron Dev. Lett. 1999, 1, 48-50. [CrossRef]

8. Lyding, J.W.; Hess, K.; Kizilyalli, I.C. Reduction of hot electron degradation in metal oxide semiconductor transistors by deuterium processing. Appl. Phys. Lett. 1996, 10, 2526-2528. [CrossRef]

9. $\mathrm{Bu}, \mathrm{J} . ;$ White, M.H. Effects of two-step high temperature deuterium anneals on SONOS nonvolatile memory devices. IEEE Electron Device Lett. 2001, 1, 17-19.

10. Mertens, H.; Ritzenthaler, R.; Arimura, H.; Franco, J.; Sebaai, F.; Hikavyy, A.; Pawlak, B.J.; Machkaoutsan, V.; Devriendt, K.; Tsvetanova, D.; et al. Si-cap-free SiGe p-channel FinFETs and gate-all-around transistors in a replacement metal gate process: Interface trap density reduction and performance improvement by highpressure deuterium anneal. In Proceedings of the Symposium on VLSI Technology, Kyoto, Japan, 16-18 June 2015; pp. T142-T143.

11. Chang, H.S.; Hwang, H. Enhancement of Data Retention Time for 512-Mb DRAMs Using High-Pressure Deuterium Annealing. IEEE Trans. Electron Devices 2008, 12, 3599-3601. [CrossRef]

12. Arora, N. MOSFET Models for VLSI Circuit Simulation, 1st ed.; Springer: New York, NY, USA, 1993; p. 167.

13. Lee, J.; Cheng, K.; Chen, Z.; Hess, K.; Lyding, J.W.; Kim, Y.-K.; Lee, H.-S.; Kim, Y.-W.; Suh, K.-P. Application of high pressure deuterium annealing for improving the hot carrier reliability of CMOS transistors. IEEE Electron Device Lett. 2000, 21, $221-223$.

14. Chasin, A.; Franco, J.; Bury, E.; Ritzenthaler, R.; Litta, E.; Spessot, A.; Horiguchi, N.; Linten, D.; Kaczer, B. Relevance of fin dimensions and high-pressure anneals on hot-carrier degradation. In Proceedings of the 2020 IEEE International Reliability Physics Symposium (IRPS), Dallas, TX, USA, 28 April-30 May 2020.

15. Park, J.-Y.; Yoo, T.J.; Yu, J.-M.; Lee, B.-H.; Choi, Y.-K. Impact of Post-Metal Annealing with Deuterium or Nitrogen for Curing a Gate Dielectric Using Joule Heat Driven by Punch-Through Current. IEEE Electron Device Lett. 2020, 42, 276-279. [CrossRef]

16. Yu, J.M.; Park, J.Y.; Yoo, T.J.; Han, J.K.; Yun, D.H.; Lee, G.B.; Hur, J.; Lee, B.H.; Kim, S.Y.; Lee, B.H.; et al. Quantitative analysis of high-pressure Deuterium annealing effects on vertically stacked Gate-All-Around SONOS memory. IEEE Trans. Electron. Devices 2020, 67, 3903-3907. [CrossRef]

17. Sung, J.-Y.; Jeong, J.-K.; Ko, W.-S.; Byun, J.-H.; Lee, H.-D.; Lee, G.-W. High Pressure Deuterium Passivation of Charge Trapping Layer for Nonvolatile Memory Applications. Micromachines 2021, 12, 1316. [CrossRef] [PubMed] 